\title{
CONCESSION POLICY AND PRACTICE AT THE RUSSIAN FAR EAST IN 1920-1940S: TRADE-OFFS AND RESULTS
}

\author{
Taisiya V. Yudina \\ Volgograd State University, Volgograd, Russian Federation
}

\begin{abstract}
Modern political leverage from western countries to Russia allows researchers to use domestic historical experience of 1920-1940s. International isolation of Soviet Russia induced the search of different ways out, including making concessionary agreements with foreign entrepreneurs. Since 1921 concessionary agreements were made between Soviet Russia/USSR and Germany, England, USA, Japan, Norway, Poland, Austria, Italy, France, Persia, Denmark, Finland, Latvia, Holland, Sweden, Estonia, Lithuania, Turkey, China and Mongolia. Soviet economy began attracting private foreign capital.

At the end of the 1920s Soviet government set a course to liquidate private property. Share of concessionary enterprises in the national economy decreased. But despite the absence of any new concessionary agreements since 1929, concessionary affairs in USSR lasted till mid-1940 and only with Japan because of its deep political meaning.

The author analyzes Japan concessions' activity, such as "Kita Karafuto Koogio Kabusiki Kaisha" and "Kita Karafuto Sekio Kabusiki Kaisha" in 1930-1940s (pre- and World War II period), workers' socio-economic conditions, relations between Japanese concessioners and Soviet authorities. Permanent infringements of concessionary agreements by Japan concessioners including concessions workers' food and goods supply, price making, Soviet workers' housing provision and dismissal, meeting safety requirements were registered. However, neither Japan concessioners dissolve their enterprises nor Soviet authorities annulled concessionary agreements. The author concludes that originally in 1925 granting concessions to Japan businessmen in USSR was among the conditions of Japan government diplomatic recognition of USSR. Further Japan concessions in USSR were deterrent factor from Japan military invasion to the Russian Far East.
\end{abstract}

Key words: Japanese concessioners, concession agreements, foreign political interests, Far East, USSR, Japan.

УДК 94(47+51)“1920/1940”

Дата поступления статьи: 16.03.2016

ББК 63.3(2)6-2

Дата принятия статьи: 17.05.2016

\section{КОНЦЕССИОННАЯ ПОЛИТИКА И ПРАКТИКА НА ДАЛЬНЕМ ВОСТОКЕ В 1920-1940-е ГГ.: КОМПРОМИССЫ И РЕЗУЛЬТАТЫ}

\section{Таисия Васильевна Юдина}

Волгоградский государственный университет, г. Волгоград, Российская Федерация

\begin{abstract}
Аннотация. В статье проанализированы вопросы взаимоотношений японских концессионеров с советскими органами власти по соблюдению предпринимателями советского законодательства о труде, концессионных договоров в 1920-1940-е годы. Выяснено, что неисполнение японскими предпринимателями основных положений концессионных соглашений со второй половины 1930-х гг. объяснялось особой позицией советских органов власти. Последние не требовали немедленного устранения нарушений, как это наблюдалось ранее, а стремились урегулировать вопросы на самих концессионных предприятиях с концессионерами ㄴ. и тем самым не допустить осложнений в отношениях с Японией как в предвоенные, так и в военные годы.

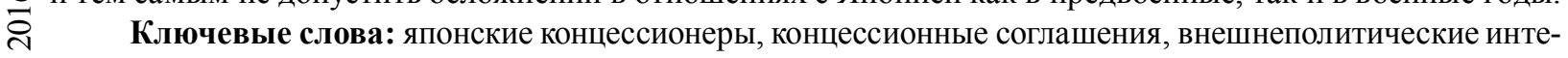
ю̊ ресы, Дальний Восток, СССР, Япония.
\end{abstract}

В современных экономических и политических условиях на Российскую Федерацию вновь оказывают жесткое давление государства Запада и Востока, США, фактически 
изолируя ее от внешнего мира. Похожие ситуации наблюдались и в прошлом веке. Тогда Советская Россия искала разными путями выход из международной изоляции, в том числе и через оформление концессионных договоров с иностранными юридическими и физическими лицами. Первые концессионные договоры в Советской России были заключены в 1921 году. На протяжении 1920-х гг. с помощью концессионных договоров в СССР привлекались германский, английский, японский и другие иностранные капиталы, устанавливались международные отношения.

Начиная с 1929 г. в нашей стране не было заключено ни одного нового концессионного договора, что свидетельствовало об угасании концессионной практики и выходе из международной изоляции. Однако концессионные отношения в 1930-х гг. не отменялись и не запрещались, иначе не наблюдалось бы присутствие японской рыболовной концессии на Камчатке даже в 1945 году [3, с. 211]. К середине 1930-х гг. в СССР действовало 11 иностранных концессий, 4 из которых принадлежали японскому капиталу [17, с. 107]. На 1 января 1937 г. в Советском Союзе оставалось всего пять концессионных предприятий. Четыре из них были японскими: три действовали в нефтяной и угольной промышленности Северного Сахалина, а одна эксплуатировала водные биоресурсы Камчатки. Даже по состоянию на 30 марта 1944 г. японские концессии «Кита Карафуто Секию Кабусики Кайша» (нефтяная), «Кита Карафуто Коогио Кабусики Кайша» (угольная) и «Ничиро Гиогио Кабусики Кайша» (рыбопромышленная) продолжали фигурировать в конфиденциальной советской статистике. Самой последней концессией в СССР стала камчатская концессия «Ничиро Гиогио Кабусики Кайша». Она была ликвидирована в августе 1945 года [18, с. 277]. При этом экономические отношения СССР с Японией на протяжении всей концессионной практики имели под собой глубокий политический подтекст, стремление извлечь определенные политические дивиденды. Подтверждением этому тезису является изученная нами деятельность конкретного концессионного предприятия «Кита Карафуто Коогио Кабусики Кайша» (концессионный договор был заключен в 1925/ 26 г.). В 1925 г. одним из условий дипломати- ческого признания СССР со стороны японского правительства стало предоставление Советским Союзом концессий японским предпринимателям. Процесс ликвидации концессионной практики в конце 1920 -х - начале 1930-х гг. не коснулся японских концессий на советском Дальнем Востоке. Внешнеполитический фактор в отношениях между СССР и Японией оказался преобладающим, хотя отношения концессионных дальневосточных предприятий с советскими органами власти по производственно-социальным вопросам оставались очень сложными и напряженными, особенно со второй половины 1930-х годов. Так, на существование японских концессий в СССР не повлияло заключение японо-германского «антикоминтерновского пакта» 25 января 1936 года. В 1938-1939 гг. вооруженные столкновения СССР с Японией у озера Хасан и на реке Халхин-Гол осложнили, но не прекратили концессионных отношений между двумя странами на Дальнем Востоке. В сентябре 1937 г. советские власти запретили концессионеру «Кита Карафуто Коогио Кабусики Кайша» эксплуатацию шахты в районе Агнево на Северном Сахалине, однако официального расторжения концессионного соглашения не произошло. Концессионер продолжал добывать уголь в районе Дуэ (Северный Сахалин) для местных нужд и вывозить его запасы в Японию [4, с. 127].

Проверяющие советские надзорные органы, руководство Западно-Сахалинского горного округа постоянно отмечали нарушения концессионного договора концессионером «Кита Карафуто Коогио Кабусики Кайша», информируя об этом Народный комиссариат тяжелой промышленности СССР [8, л. 192193]. Нарушения касались вопросов снабжения работников концессии продуктами питания и товарами, установления цен на реализуемую продукцию, предоставления жилья советским рабочим, их увольнения, невыполнения требований советских органов по вопросам устранения замечаний по технике безопасности. В то же время японский директор «Кита Карафуто Коогио Кабусики Кайша» Мурояма обвинял советскую сторону в незаконном уголовном осуждении японских инженеров и требовал их освобождения под угрозой закрытия угольных шахт. При этом 
концессионер поддерживал предписания Горного округа о закрытии шахт. В таких сложных условиях часть японских инженеров уезжали на родину, оставшиеся не изъявляли желания заведовать шахтами, а представителям советских органов власти приходилось находить компромиссы с концессионером по налаживанию производственного процесса, соблюдать советское трудовое законодательство по вопросам труда и быта советских и японских рабочих.

В это же время представители японского концессионера предпринимали различные меры к закрытию концессии. Так, с апреля по сентябрь 1937 г. дирекция концессии под разными выдуманными предлогами пыталась увольнять советских рабочих, такими как прогулы (280 чел.), окончание работ на шахтах (106 чел.), невозможность снабжения рабочих питанием и товарами [8, л. 192; 9 , л. 167 ; 10, л. 157]. Руководство советского надзорного органа - Западно-Сахалинского горного округа, получая провокационные письма от доверенных японского концессионера, предлагало «в категоричной форме немедленно обеспечить рабочих и их семьи всеми видами продовольствия и товарами широкого потребления, предусмотренными коллективным договором» и добавляло: «В противном мы вынуждены будем рассматривать данное положение как нарушение кониессионного договора со стороны Концессионного общества» [10, л. 157].

Такое деловое обращение начальника Западно-Сахалинского горного округа Вовченко к доверенному представителю концессии Мурояма имело свои результаты. Директор Мурояма в ответном письме подробно расписал, какие продукты отпускаются, какие не разрешают таможенные органы реализовывать, что не успели завезти еще из Японии, не преминув при этом заметить: «сообщаем Вам для Вашего сведения о том, что Концессионный договор не обязывает Общество снабжать рабочих продуктами» [5, л. 158].

Таким образом, представленная переписка свидетельствует, с одной стороны, о постоянных трудностях в деятельности концессионного предприятия и сложных взаимоотношениях японских предпринимателей и представителей советских органов власти; с другой стороны, об отсутствии реальных дей- ствий японского концессионера по ликвидации концессии и советских органов власти - по расторжению концессионного договора. Аналогичная ситуация наблюдалась и на японской нефтяной концессии «Кита Карафуто Секию Кабусики Кайша». Действительно, «внешнеполитический фактор в условиях Дальнего Востока (особенно в отношениях СССР и Японии) доминировал над внутриполитическими установками, направленными на свертывание концессионного дела. Поэтому, несмотря на то что на Дальнем Востоке в конце 1920-х начале 1930-х гг. так же, как и в целом по стране, происходило свертывание концессионной политики и самой практики, этот процесс практически не затронул основные японские концессионные предприятия» [12], продолжавшие работать в 1930-1940-е годы.

В 1937 г. начальник иностранного отдела (ИНО) Народного комиссариата тяжелой промышленности (НКТП) СССР Кашицин требовал от начальника Западно-Сахалинского горного округа Вовченко не наказания японского концессионера за продажу мясных консервов с содержанием свинца, что было подтверждено результатами исследования, а принятия мер, «чтобы в продажу поступали только доброкачественные продукты» [14, л. 60, 156]. В то же время ИНО НКТП, обращаясь для проведения экспертизы новой партии мясных японских консервов к директору Московского научно-исследовательского санитарного института им. Эрисмана Эттингеру, просит взять «под непосредственное наблюдение это дело, учитывая его политическое значение» [6, л. 141].

В иностранный сектор Народного комиссариата тяжелой промышленности СССР для разрешения сложных вопросов нередко обращались и сами концессионеры, получая положительные заключения от ИНО НКТП. Так, в письме от 29 ноября 1937 г. в НКТП СССР представитель «Кита Карафуто Коогио Кабусики Кайша» Сакагуци попросил оставить на Сахалине для работников концессии завезенные продукты из Японии без разрешения Торгпредства СССР в Токио, но с устного разрешения начальника Западно-Сахалинского горного округа, дав «указание начальнику оформить письменное разрешение, а Александровской таможне - не конфисковывать про- 
дукты питания» с учетом того, что навигация будет закрыта до мая 1938 г. и завезти продукты до этого времени не будет возможности [11, л. 403].

По причине соблюдения «политических интересов» с Японией также не улучшались жилищно-бытовые условия советских концессионных рабочих на японских предприятиях. Несмотря на многочисленные акты и другие документы об «отвратительных жилищнобытовых условиях» на «Кита Карафуто Коогио Кабусики Кайша», концессионер ограничивался только обещаниями улучшить условия проживания рабочих и членов их семей. При этом скученность в бараках, отсутствие надлежащих санитарных условий вызывают не только «частые эпидемические заболевания, но и приводят к увеличению количества смертных случаев среди детей рабочих концессии» [7, л. 113], отмечал инспектор труда Западно-Сахалинского горного округа при обследованиях предприятия.

Организация лечебной помощи на указанном концессионном предприятии также требовала значительных средств концессионера: это строительство новой больницы, амбулаторных пунктов, формирование штата медицинского персонала. Но концессионер, несмотря на постоянные требования советских органов власти и рост несчастных случаев на производстве среди рабочих, в том числе и японских, не улучшал медицинское обслуживание советских и японских работников, а советские органы власти не предпринимали мер ни по строительству новых медицинских учреждений, ни по наказанию предпринимателя.

В социокультурной среде условия на «Кита Карафуто Коогио Кабусики Кайша» до конца 1930-х гг. так и не изменились в лучшую сторону, но концессия продолжала работать.

Япония пообещала ликвидировать все концессии в СССР до конца 1941 г., дав письменное обязательство, но Великая Отечественная война сорвала эти планы. В сложной военно-политической обстановке Советский Союз с целью недопущения осложнений в отношениях с Японией не настаивал на ликвидации концессий. В октябре 1941 г. японской стороне было даже продлено право на добычу и вывоз нефти на «Кита Карафуто
Секию Кабусики Кайша» до 1943 года. Именно экономическими уступками (нефть была жизненно необходима Японии) в СССР стремились избежать войны на востоке [4, с. 125126]. На угольной концессии «Кита Карафуто Коогио Кабусики Кайша» продолжали трудиться японские рабочие и служащие: 1 января [15, л. 316] и 1 марта 1943 г. их насчитывалось 80 человек [16, с. 213-215], русских 99 человек [15, л. 316]. Для японских рабочих, например на руднике Дуэ указанной концессии, отдельно работали артельная столовая, баня, проживали они отдельно от русских рабочих. Однако по выводам двухсторонней советско-японской комиссии жилищные условия японских и советских рабочих мало чем отличались друг от друга: в отдельных домах требовался косметический ремонт, в других капитальный, и данные предписания не зависели от подданства проживающих. Примечательно другое: по нашим подсчетам, было обследовано 49 домов - 29 двухэтажных (4- и 6-квартирных) домов, где проживали рабочие и служащие; 13 домов пустовали и в 7 домах жильцы проживали только на нижних этажах [2, л. 293-296]. То есть рабочих и служащих на концессии оставалось все меньше, на 1 марта 1943 г. японских и русских работников вместе с иждивенцами насчитывалось 443 человека [15, л. 324]. В августе же 1940 г. только «недоснабженных» японских и советских рабочих угольной концессии предметами широкого потребления имелось 1009 человек [13, л. 245] (точную цифру всех рабочих вместе с иждивенцами установить не удалось. - T. Ю.). Отметим еще одну особенность, которая не была характерна для концессионной практики и политики советского правительства в 1920-1930-е гг.: отстаивание трудовых прав иностранных рабочих. Однако защита их трудовых интересов представителями советских органов власти практиковалась на японских концессиях. Так, инспектор труда Западно-Сахалинского округа установил факты «недоначисления и недоплаты» семи японским кочегарам в марте и апреле 1940 г. в общей сумме 248 руб. 89 коп. и потребовал от концессионера произвести доплату [1, л. 286].

Таким образом, после ликвидации всех концессий в СССР японские «Кита Карафуто 
Секию Кабусики Кайша» (нефтяная), «Кита Карафуто Коогио Кабусики Кайша» (угольная) и «Ничиро Гиогио Кабусики Кайша» (рыбопромышленная) продолжали действовать на Северном Сахалине и Камчатке.

Внешняя политика СССР в полной мере смогла воспользоваться самим фактом существования японских концессий в советском дальневосточном регионе. Советский Союз сумел «вычислить» ту теснейшую связь, которая существовала между японскими политическими, военными и деловыми кругами в период до и во время Второй мировой войны [18, с. 276-277]. Концессии явились фактором сдерживания Японии от военного вторжения на советский Дальний Восток, поскольку Северный Сахалин являлся поставщиком нефти и угля для японской милитаризованной экономики, причем производственная и транспортная инфраструктура для освоения и вывоза топлива создавалась японскими служащими и рабочими.

\section{СПИСОК ЛИТЕРАТУРЫ}

1. Акт, составленный инспектором труда Западно-Сахалинского горного округа и представителями Дуйского рудничного комитета союза Угольщиков, и концессии «Кита Карафуто Коогио Кабусики Кайша» от 13 апреля 1940 года // Российский государственный архив экономики (РГАЭ). Ф. 8225. - Оп. 1. - Д. 5269. - Л. 286.

2. Акты, составленные представителями Дуйского рудничного комитета союза Угольщиков, Западно-Сахалинского горного округа и концессии «Кита Карафуто Коогио Кабусики Кайша» от 23 и 25 марта 1943 года // РГАЭ. - Ф. 8225. - Оп. 1. Д. 5269. - Л. 293-296.

3. Булатов, В. В. Концессионные отношения в СССР / В. В. Булатов. - Волгоград : Изд-во ВолГУ, 2011. $-226 \mathrm{c}$.

4. Булатов, В. В. Японские концессии на Северном Сахалине как инструмент советской внешней политики / В. В. Булатов // Власть. - 2008. № 11. - С. 124-128.

5. Информационное письмо директора «Кита Карафуто Коогио Кабусики Кайша» начальникуЗападно-Сахалинского горного округа от 21.08.1937 г. // РГАЭ. - Ф. 7297. - Оп. 28. - Д. 127. - Л. 158.

6. Информационное письмо ИНО НКТП Московскому научно-исследовательскому санитарному институту им. Эрисмана от 19.08.1937 г. // РГАЭ. Ф. 7297. - Оп. 28. - Д. 127. - Л. 141.
7. Информационное письмо инспектора труда Западно-Сахалинского горного округа в ИНО Наркомтяжпром от 06.1937 г. // РГАЭ. - Ф. 7297. Оп. 28. - Д. 127. - Л. 112-113.

8. Информационное письмо начальника Западно-Сахалинского горного округа от 26.08.1937 г. в Главуголь // РГАЭ. - Ф. 7297. - Оп. 28. - Д. 127. Л. 192-193.

9. Информационное письмо начальника Западно-Сахалинского горного округа от 02.09.1937 г. в Главуголь // РГАЭ. - Ф. 7297. - Оп. 28. - Д. 127. - Л. 167.

10. Информационное письмо начальника Западно-Сахалинского горного округа от 07.08.1937 г. доверенному концессионного общества «Кита Карафуто Коогио Кабусики Кайша» // РГАЭ. Ф. 7297. - Оп. 28. - Д. 127. - Л. 157.

11. Информационное письмо представителя угольной концессии общества «Кита Карафуто Коогио Кабусики Кайша» в Наркомтяжпром СССР от 29.11.1937 г. // РГАЭ. - Ф. 7297. - Оп. 28. Д. 127. - Л. 403.

12. Исаев, А. А. Социально-политические настроения на японских концессиях о. Сахалин в 1930-е - начале 1940-х гг. / А. А. Исаев // Ойкумена. - 2009. - № 4. - С. 78-82. - Электрон. текстовые дан. - Режим доступа: http://www.ojkum.ru/arc/lib/ 2009_04_12.pdf(дата обращения: 08.02.2016). -Загл. с экрана.

13. Определение судебной коллегии по гражданским делам Верховного суда РСФСР // РГАЭ. Ф. 8225. - Оп. 1. - Д. 5269. - Л. 245.

14. Письмо начальника ИНО НКТП начальнику Западно-Сахалинского горного округа от 26.08.1937 г. // РГАЭ. - Ф. 7297. - ОП. 28. - Д. 127. - Л. 60, 156.

15. Сведения о количестве иждивенцев на 1-ое января и на 1-ое марта 1943 г. // РГАЭ. - Ф. 8225. Оп. 1. - Д. 5269. - Л. 316, 324.

16. Труд на концессионных предприятиях Российской империи и СССР (1900-1940-е годы): Документы и материалы / под общ. ред. Т. В. Юдиной. Волгоград : Изд-во ВолГУ, 2015. - 480 с.

17. Хромов, С. С. Иностранные концессии в СССР. Исторический очерк. Документы. В 2 ч. Ч. ІІ / С. С. Хромов. - М. : Институг российской истории PAH, 2006. $-404 \mathrm{c}$.

18. Юдина, Т. В. Японцы на российском Дальнем Востоке (1900-е - начало 1930-х гг.): Проблема рабочей силы на Камчатке и Северном Сахалине / Т. В. Юдина, В. В. Булатов, Е. Л. Фурман // Былые годы. - 2014. - № 32 (2). - С. 276-281.

\section{REFERENCES}

1. Akt, sostavlennyy inspektorom truda ZapadnoSakhalinskogo gornogo okruga i predstavitelyami 
Duyskogo rudnichnogo komiteta soyuza Ugolshchikov, i kontsessii "Kita Karafuto Koogio Kabusiki Kaysha" ot 13 aprelya 1940 goda [Act, Drawn by West-Sakhalin Mountain District Labor Inspector and Coalers Union Due Mine Committee Representatives, and Concession Kita Karafuto Koogio Kabusiki Kaisha Representatives of April 13, 1940]. Rossiyskiy gosudarstvennyy arkhiv ekonomiki [Russian State Economic Archive], F. 8225, Op. 1, D. 5269, L. 286.

2. Akty, sostavlennye predstavitelyami Duyskogo rudnichnogo komiteta soyuza Ugolshchikov, ZapadnoSakhalinskogo gornogo okruga i kontsessii "Kita Karafuto Koogio Kabusiki Kaysha" ot 23 i 25 marta 1943 goda [Acts Drawn by Representatives of Coalers Union Due Mine Committee, West-Sakhalin Mountain District and Kita Karafuto Koogio Kabusiki Kaisha Concession of 23 and 25 March, 1943]. Rossiyskiy gosudarstvennyy arkhiv ekonomiki [Russian State Economic Archive], F. 8225, Op. 1, D. 5269, L. 293-296.

3. Bulatov V.V. Kontsessionnye otnosheniya $v$ SSSR [Concession Relations in the USSR]. Volgograd, Izd-vo VolGU, 2011. 226 p.

4. Bulatov V.V. Yaponskie kontsessii na Severnom Sakhaline kak instrument sovetskoy vneshney politiki [Japanese Concessions at Northern Sakhalin as Soviet Foreign Policy Instrument]. Vlast, 2008, no. 11, pp. 124-128.

5. Informatsionnoe pismo direktora "Kita Karafuto Koogio Kabusiki Kaysha" nachalniku Zapadno-Sakhalinskogo gornogo okruga ot 21.08 .1937 g. [Information Letter of Kita Karafuto Koogio Kabusiki Kaisha Concession Director to WestSakhalin Mountain District Chief of August 21, 1937]. Rossiyskiy gosudarstvennyy arkhiv ekonomiki [Russian State Economic Archive], F. 7297, Op. 28, D. 127, L. 158 .

6. Informatsionnoe pismo INO NKTP Moskovskomu nauchno-issledovatelskomu sanitarnomu institutu im. Erismana ot 19.08.1937 g. [Information Letter of Heavy Industry People's Commissariat Foreign Office to Erisman's Moscow Sanitary Science Institute of August 19, 1937]. Rossiyskiy gosudarstvennyy arkhiv ekonomiki [Russian State Economic Archive], F. 7297, Op. 28, D. 127, L. 141.

7. Informatsionnoe pismo inspektora truda Zapadno-Sakhalinskogo gornogo okruga v INO Narkomtyazhprom ot 06.1937 g. [Information Letter of West-Sakhalin Mountain District Labor Inspector to Heavy Industry People's Commissariat Foreign Office of June 1937]. Rossiyskiy gosudarstvennyy arkhiv ekonomiki [Russian State Economic Archive], F. 7297, Op. 28, D. 127, L. 112-113.

8. Informatsionnoe pismo nachalnika ZapadnoSakhalinskogo gornogo okruga ot 26.08.1937 g. v Glavugol [Information Letter of West-Sakhalin Mountain District Chief to Glavugol of August 26,
1937]. Rossiyskiy gosudarstvennyy arkhiv ekonomiki [Russian State Economic Archive], F. 7297, Op. 28, D. 127, L. 192-193.

9. Informatsionnoe pismo nachalnika ZapadnoSakhalinskogo gornogo okruga ot 02.09.1937 g. v Glavugol [Information Letter of West-Sakhalin Mountain District Chief to Glavugol of September 2, 1937]. Rossiyskiy gosudarstvennyy arkhiv ekonomiki [Russian State Economic Archive], F. 7297, Op. 28, D. 127, L. 167.

10. Informatsionnoe pismo nachalnika ZapadnoSakhalinskogo gornogo okruga ot 07.08.1937 g. doverennomu kontsessionnogo obshchestva "Kita Karafuto Koogio Kabusiki Kaysha" [Information Letter of West-Sakhalin Mountain District Chief to Kita Karafuto Koogio Kabusiki Kaisha Concession Attorney of August 7, 1937]. Rossiyskiy gosudarstvennyy arkhiv ekonomiki [Russian State Economic Archive], F. 7297, Op. 28, D. 127, L. 157.

11. Informatsionnoe pismo predstavitelya ugolnoy kontsessii obshchestva "Kita Karafuto Koogio Kabusiki Kaysha” v Narkomtyazhprom SSSR ot 29.11.1937 g. [Information Letter of Kita Karafuto Koogio Kabusiki Kaisha Coal Concession Representative to USSR Heavy Industry People's Commissariat of November 29, 1937]. Rossiyskiy gosudarstvennyy arkhiv ekonomiki [Russian State Economic Archive], F. 7297, Op. 28, D. 127, L. 403.

12. Isaev A.A. Sotsialno-politicheskie nastroeniya na yaponskikh kontsessiyakh o. Sakhalin v 1930-e nachale 1940-kh gg. [Politico-Social Moods of Japanese Concessions at Sakhalin Island in 1930s Beginning of 1940s]. Oykumena, 2009, no. 4, pp. 7882. Available at: http://www.ojkum.ru/arc/lib/ 2009_04_12.pdf. (accessed February 8, 2016).

13. Opredelenie sudebnoy kollegii po grazhdanskim delam Verkhovnogo suda RSFSR [Judical Division Decision of Civil Cases of RSFSR Supreme Court]. Rossiyskiy gosudarstvennyy arkhiv ekonomiki [Russian State Economic Archive], F. 8225, Op. 1, D. 5269, L. 245.

14. Pismo nachalnika INO NKTP nachalniku Zapadno-Sakhalinskogo gornogo okruga ot 26.08.1937 g. [Letter of Heavy Industry People's Commissariat Foreign Office District Chief to West-Sakhalin Mountain District Chief of August 26, 1937]. Rossiyskiy gosudarstvennyy arkhiv ekonomiki [Russian State Economic Archive], F. 7297, Op. 28, D. 127, L. 60, 156.

15. Svedeniya o kolichestve izhdiventsev na $1-$ oe yanvarya i na 1-oe marta 1943 goda [Dependents Quantity Data as of January 1 and March 1, 1943]. Rossiyskiy gosudarstvennyy arkhiv ekonomiki [Russian State Economic Archive], F. 8225, Op. 1, D. 5269, L. 316, 324.

16. Yudina T.V., ed. Trud na kontsessionnykh predpriyatiyakh Rossiyskoy imperii i SSSR (19001940-e gody): Dokumenty i materialy [Labour on 
Concessions of Russian Empire and USSR (1900-1940): Documents and Archive Materials]. Volgograd, Izdvo VolGU, 2015. 480 p.

17. Khromov S.S. Inostrannye kontsessii v SSSR. Istoricheskiy ocherk. Dokumenty. V 2 ch. Ch. II [Foreign Concessions in the USSR. Historical Review. Documents. In 2 parts. Part 2]. Moscow, Institut rossiyskoy istorii RAN Publ., 2006. 404 p.
18. Yudina T.V., Bulatov V.V., Furman E.L. Yapontsy na rossiyskom Dalnem Vostoke (1900-e nachalo 1930-kh gg.): Problema rabochey sily na Kamchatke i Severnom Sakhaline [Japanese at Russian Far East (1900 - Beginning of 1930s): Problem of Russian Labour Force at Kamchatka and Northern Sakhalin]. Bylye gody, 2014, no. 32 (2), pp. 276-281.

\section{Information About the Author}

Taisiya V. Yudina, Doctor of Sciences (History), Professor, Department of History of Russia, Volgograd State University, Prosp. Universitetsky, 100, 400062 Volgograd, Russian Federation, taisia.yudina@volsu.ru, histrus@volsu.ru.

\section{Информация об авторе}

Таисия Васильевна Юдина, доктор исторических наук, профессор кафедры истории России, Волгоградский государственный университет, просп. Университетский, 100, 400062 г. Волгоград, Российская Федерация, taisia.yudina@,volsu.ru, histrus@,volsu.ru. 